\title{
Human Protamines and Male Infertility
}

\author{
K. K. KHARA, ${ }^{1}$ M. VLAD,${ }^{1,3}$ M. GRIFFITHS, ${ }^{2}$ and C. R. KENNEDY ${ }^{2}$
}

Submitted: August 22, 1996

Accepted: January 7, 1997

Purpose: Our purpose was to determine the ratio of protamine 1 to protamine 2 in human spermatozoa and relate it to in vitro fertilization rates (IVF) and standard semen parameters.

Methods: Couples who had been clinically diagnosed as having male-factor infertility and had undergone IVF treatment were grouped according to IVF rates and pregnancy outcome. Protamines were extracted and separated on acid urea polyacrylamide gels. The PI/P2 ratio correlation with semen parameters and IVF rates was investigated using nonparametric analysis.

Results: The PIIP2 ratio ranged from 0.55 to 1.29 in the control group of patients, who had fertilization rates $\geq 50 \%$ and had achieved a pregnancy in one IVF cycle. Of the test patients with IVF $<50 \%$, three (14\%) had PI/P2 ratios outside the range exhibited by the control group and their sperm possessed large heads.

Conclusions: $P 1 / P 2$ ratios were statistically negatively correlated with $I V F$ rates in the control group and with progressive motile sperm concentration in the test group. We do not think that altered PI/P2 ratios are the primary cause of reduced fertilization.

KEY WORDS: in vitro fertilization; protamines; male infertility; sperm head dimensions.

\section{INTRODUCTION}

The majority of nucleosomal histones are replaced by protamines during spermiogenesis to form mature spermatozoa (1). In human sperm protamines make up $85-90 \%$ of the nuclear proteins (2). Protamines are small (50-57 amino acids in length), highly basic proteins rich in arginine $(40-70 \%)$ and cysteine $(8-18 \%)$ (3). The basic function of protamines remains

\footnotetext{
'Molecular Medical Research Group, University of Warwick, Biological Sciences, Gibbet Hill Road, Coventry CV4 7AL, UK.

2 The Assisted Conception Unit, Walsgrave Hospital, Walsgrave, Coventry CV2 2DX, UK.

${ }^{3}$ To whom correspondence should be addressed.
}

unknown. Current hypotheses are (a) condensation of the male genome and streamlining of the sperm nucleus, (b) protection of the genetic message delivered by the spermatozoa, and (c) generation of an imprinted state of the male genome (4). It is clear that protamines neutralize the DNA charge and aid condensation of the chromatin (1). This is believed to be achieved by oxidation of cysteine residues during epididymal transit to form intra- and intermolecular disulphide bridges, thus making the chromatin mechanically and chemically stable, transcriptionally inactive, and resistant to damage and cell reactivation other than by an oocyte at fertilization $(5,6)$.

There are two families of protamines, P1 (6675 $\left.M_{r}\right)$ and $\mathrm{P} 2\left(7636-7242 M_{r}\right)(22,23)$. P1 is found throughout the animal kingdom, whereas $\mathrm{P} 2$ has been isolated only in humans and a few other mammals (mouse, hamster and stallion) studied to date (7-12). The P2 gene has, however, been shown to exist in the genomes of bull and boar (13), despite their lacking the P2 protein. In human sperm of fertile men P1 and P2 are found at the ratio of approximately 1:1 (2). Previous studies have reported differences in the level of $\mathrm{Pl}$ and $\mathrm{P} 2$ between fertile and infertile men, with infertile patients showing in excess of $25 \%$ sperm with abnormally large heads $(2,10,14-16)$.

The fertilizing potential of semen samples has been shown to be related to sperm concentration, total sperm count, progressive motile sperm concentration, and normal sperm morphology, which are routinely measured in semen analysis prior to IVF $(17,18)$; sperm head dimensions $(19,20)$; the absence of histones in mature sperm nuclei $(14,21,22)$; and the presence of double-stranded DNA $(23,24)$. Little attention has been given to $\mathrm{P} 1$ and $\mathrm{P} 2$ levels, the correlation with in vitro fertilization (IVF) rates, and the characteristics of mature sperm. The aim of this study was to determine $\mathrm{PI} / \mathrm{P} 2$ ratios in male patients undergoing IVF and correlate it with IVF fertilization rates, standard semen parameters, sperm head dimensions, the persistence of histone in mature sperm heads, and the state 
of the DNA (i.e., single or double stranded) in mature sperm heads.

\section{MATERIALS AND METHODS}

All materials were obtained from Sigma Chemical Company (Fancy Road, Dorset, UK) unless otherwise stated.

\section{Couple Selection}

One hundred eighty couples who had undergone IVF at the Assisted Conception Unit, Walsgrave Hospital, Coventry, between $1 / 1 / 93$ and $11 / 11 / 94$, clinically diagnosed to have no determined female-factor infertility, were contacted retrospectively to participate in this study. The research project was approved by the local ethics committee. Thirty-three patients agreed to participate and went on to donate semen samples for analysis. The patients were grouped according to their IVF rates and pregnancy outcome. When there was more than one IVF cycle performed during this period the fertilization rates for the last two cycles were averaged to ensure a more representative IVF fertilization rate was achieved. Fertilization was considered to be achieved when two or more pronuclei were observed. The control group ( $\mathrm{C} ; n=12 ; 12$ IVF cycles) consisted of patients with an IVF rate $\geq 50 \%$ and who had achieved a pregnancy in one IVF cycle. The test patients were divided into two groups: test group 1 (T1) and test group 2 (T2). T1 patients $(n=12,17$ IVF cycles) had either 0 or $\leq 50 \%$ fertilization for two consecutive IVF cycles ( $n=5,10$ IVF cycles) or zero fertilization in one IVF cycle but a positive fertilization test with donor sperm ( $n=7,7$ IVF cycles); T2 patients ( $n=9,9$ IVF cycles) had a reduced IVF rate $(<50 \%)$ but no donor test for the only IVF cycle they had undergone during this period. Thus group T1 had confirmed reduced fertilization, while $\mathrm{T} 2$ patients showed a potential for reduced fertilization. Table I summarizes the selection criteria used to group patients.

\section{Semen Collection and Processing}

Semen samples were produced by masturbation after a period of 2-8 days of sexual abstinence. The samples were delivered to the hospital within $30 \mathrm{~min}$ of semen production and were kept at $37^{\circ} \mathrm{C}$ until complete liquefaction had occurred. Standard semen analysis was performed within $1 \mathrm{hr}$ of production, according to the WHO (25). Semen volume, viscosity, pH, sperm concentration, total sperm count, progressive motile sperm concentration, and percentage of Papanicolaoustained sperm with normal morphology were recorded for each semen sample. Sperm smears for staining with Feulgen, acidic aniline blue, and acridine orange were also prepared. Following semen analysis and smearing, the remaining liquefied semen was aliquoted and frozen in liquid nitrogen. Each aliquot contained a total spermatozoa count ranging from $8 \times 10^{6}$ to $14 \times$ $10^{6}$. Preliminary experiments had shown these sperm concentrations to contain sufficient basic nuclear proteins to be detected by our gel electrophoresis system. All the samples were labeled and stored in liquid nitrogen until further processing.

\section{Extraction of Basic Nuclear Proteins and Gel Electrophoresis}

Basic nuclear proteins were extracted from frozen sperm cells and analyzed by acid urea polyacrylamide gel electrophoresis according to the method described by de Yebra and Oliva (26). Gel electrophoresis was performed on $16 \times 19.5-\mathrm{cm}$ gels containing $0.9 \mathrm{M}$ acetic acid, $2.5 \mathrm{M}$ urea, $15 \%$ acrylamide, $0.09 \%$ bisacrylamide, $0.24 \%$ ammonium persulfate, and $0.6 \% \mathrm{~N}$, $N, N^{p}, N$-tetramethylethylenediamine. Following polymerization the gel was allowed to stand for at least 30 min and preelectrophoresed for $1-2 \mathrm{hr}$ at $150 \mathrm{~V}$ before loading the samples. Basic nuclear proteins extracted from each semen sample were dissolved in $15 \mu \mathrm{l}$ of gel sample buffer consisting of $5.5 \mathrm{M}$ urea, 20\% 2mercaptoethanol, and $5 \%$ acetic acid (w/v). This mixture was left on ice for at least $1 \mathrm{hr}$ before being loaded onto a gel. Calf thymus histones (Boehringer Mannheim, Bell Lane, Sussex, England) were used as molecular weight markers. Following gel loading, the gel was electrophoresed for $2.5 \mathrm{hr}$ at $150 \mathrm{~V}$ in $0.9 M$ acetic acid buffer. Proteins were stained with $0.1 \%$ Coomassie brilliant blue R-250 (Bio-Rad) for $45 \mathrm{~min}$, according to the method described by de Yebra et al. (10). The gel was destained for approximately 16-17 hr $10 \%$ methanol, $10 \%$ glacial acetic acid, placed in a fixing solution for $5 \mathrm{~min}$, and finally, transferred to $20 \%$ glycerol solution for a further $30 \mathrm{~min}$. The gel was then dried between two sheets of cellophane film. The band intensity was quantified using a Molecular Dynamics (MD) Image Quant Fast Scan densitometer (Version 3.3) with the 1q 3.3 program (MD Image Quant Software). The dried gel was converted into a computerized image (viewed on screen with a logarithmic color setting of 0.7 to 0.06 ) by scanning each track 
Table I. Summary of Selection Criteria Used to Group Patients

\begin{tabular}{|c|c|c|c|}
\hline \multirow[b]{2}{*}{ IVF rate for } & \multicolumn{3}{|c|}{ Group $^{a}$} \\
\hline & $C(1-12)^{b}$ & $\mathrm{~T} 1(13-24)$ & $\mathrm{T} 2(25-33)$ \\
\hline I IVF cycle & $\begin{array}{l}\geq 60 \% \text { and } 1 \\
\quad \text { pregnancy; } n=12\end{array}$ & & $\begin{array}{l}0 \%, n=3 ; \\
\quad<50 \%, n=6\end{array}$ \\
\hline 2 IVF cycles & & $\begin{array}{l}0 \%, n=2 ; \leq 50 \% \\
n=3\end{array}$ & \\
\hline 1 IVF cycle \& positive donor test & & $0 \%, n=7$ & \\
\hline Total $n$ & 12 & 12 & 9 \\
\hline
\end{tabular}

${ }^{a} n=$ number of patients analyzed.

${ }^{b}$ Figures in parentheses are patient numbers.

down its center. This trace was then used to determine the P1/P2 ratio. The ratio accommodated for differences in sperm quantity from which basic nuclear proteins were extracted and loaded into each track.

\section{Sperm Smear Staining}

Feulgen staining was performed according to Cooke (27) and analyzed with a microscope (Polyvar) connected to a Quantimet 970 image analysis system (Cambridge Instruments Ltd.) at the Biomedical Science Department, Sheffield University. Feulgenstained smears were scanned using a $100 \times$ immersion oil objective with a 1.25 projector lens, giving a resolution of $0.1075 \mu \mathrm{m}$ per pixel. The head dimensions of a hundred nonoverlapping sperm heads that appeared to have a morphologically normal head shape were measured using prewritten software (28) for image analysis. The features measured were sperm head area $\left(A ; \mu \mathrm{m}^{2}\right)$, perimeter $(P ; \mu \mathrm{m})$, breadth $(\mu \mathrm{m})$, length $(\mu \mathrm{m})$, and roundness $\left[P^{2} / 4 A(28)\right]$.

\section{Acidic Aniline Blue and Acridine Orange Staining}

Approximately $20 \mu \mathrm{l}$ of liquefied semen was washed twice in $10 \mathrm{ml}$ of sterile saline $(0.9 \% \mathrm{NaCl})$; the pellet was resuspended and smeared onto three glass slides. One smear was used for acidic aniline blue staining, and the other two for acridine orange staining, including a control slide. Acidic aniline blue and acridine orange staining was performed as described by Liu and Baker (29).

Sperm smears stained with acridine orange were examined on the same day as staining using an epifluorescence microscope (Nikon) with a 490-nm excitation filter (Nikon) and a 530-nm barrier filter (Nikon) at a magnification of $1000 \times$. Spermatozoa with double- stranded DNA fluoresced green and those with denatured or single-stranded DNA fluoresced orange to yellow. Cytoplasmic droplets at the neck region also stained red due to ribonucleic acid content, but provided the head was free of red to yellow fluorescence, it was scored as normal double-stranded DNA. An additional smear was made and denatured by heating to $95^{\circ} \mathrm{C}$ for $20 \mathrm{~min}$ before staining with acridine orange and served as a positive control for single-stranded DNA.

The percentage of sperm which did not stain with acidic aniline blue (negative staining for histones) and of sperm which fluoresced green with acridine orange was determined for each sample by assessing 200 spermatozoa at a magnification of $1000 \times$.

\section{Statistical Analysis}

Nonparametric tests were used on the parameters being compared, as group size $(n)$ was small and normality could not be assumed. Spearman's rank test was used to correlate different parameters within the same group. Differences between groups for the same parameter were analyzed using the Mann-Whitney $U$ test. These tests were carried out using the package cstat (Oxtech, 1991) and significance levels were determined from tables of Rees (30). $P \leq 0.05$ was taken to be significant.

All graphs were drawn using the SPSS for Windows package (SPSS, UK Ltd., Woking, Surrey, 1993).

\section{RESULTS}

Each patient was given an identification number. Numbers 1 to 12 refer to control patients in group C, 13 to 24 refer to test patients in group $\mathrm{Tl}$, and 25 to 33 refer to test patients in group T2. All patients in 
group $C$ had achieved one pregnancy through IVF and had fertilization rates ranging from 60 to $100 \%$. In group $\mathrm{T} 1$, nine patients had $0 \%$ fertilization and three had fertilization rates of $21.4,35$, and $50 \%$. These fertilization rates were confirmed by a second IVF cycle or by a positive test with donor sperm. In group $\mathrm{T} 2$, three patients had $0 \%$ fertilization and six had fertilization rates ranging from 20 to $42.9 \%$, in one IVF cycle (Table I).

Basic nuclear proteins extracted from all samples were separated by acid urea polyacrylamide gel electrophoresis as shown in Fig. 1. The relative proportions of protamine bands were measured for each sample and the P1/P2 ratio was determined. The range of variation for the $\mathrm{P} 1 / \mathrm{P} 2$ ratio for the 12 patients in the control group was $0.55-1.29$, and that for both test groups (T1, T2) was 0.74-5.00 and 0.47-1.32, respectively. The median values for the groups were not significantly different from each other (Table II).

Image analysis of Feulgen-stained sperm revealed that test patients 22 (group T1), 29, and 31 (group T2) had larger sperm heads compared to control patients and also had $\mathrm{P} 1 / \mathrm{P} 2$ ratios outside the range covered by the control, i.e., $5.00,1.32$, and 0.47 . This suggested that sperm head size might be affected by alterations

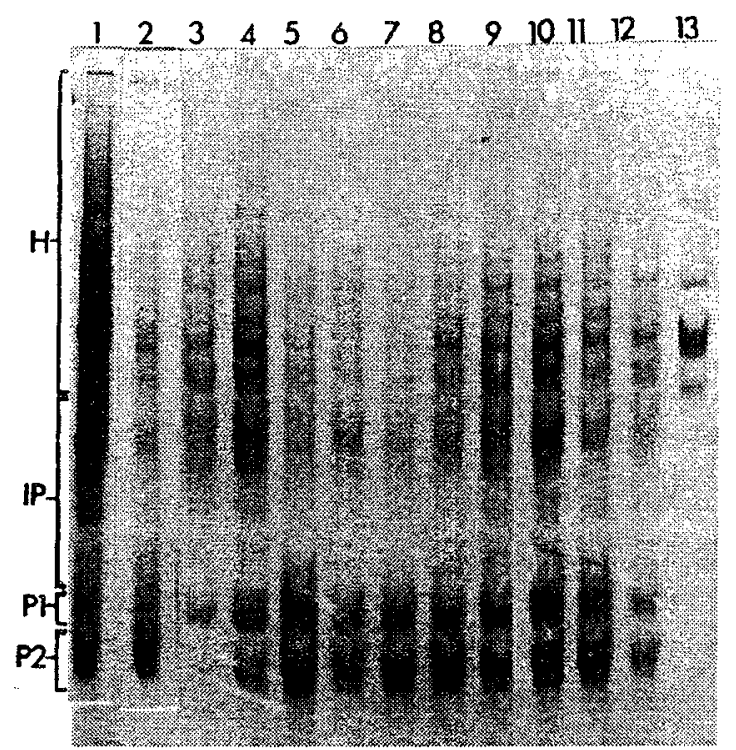

Fig. 1. Acid urea polyacrylamide gel separation of sperm basic nuclear proteins from groups $\mathrm{C}, \mathrm{T} 1$, and $\mathrm{T} 2$. Lanes 1 to 9 , test patients: $29,31,22,19,18,27,24,30$ and 25 . Lanes 10 to 12 , control patients: 5,13 , and 1. Lane 12, molecular weight standard (calf thymus histones). Histones (H); intermediate proteins (IP); protamine 1 family (Pl) refers to $\mathrm{Pl}$ and phosphorylated forms; protamine 2 family (P2) refers to mature $\mathrm{P} 2$, which occurs as two variants, $\mathrm{P} 2 \mathrm{a}$ and $\mathrm{P} 2 \mathrm{~b}$.
Table II. Group C, T1, and T2 Median and Range Values for P1/P2 Ratio and IVF Rates

\begin{tabular}{lrcc}
\hline & \multicolumn{4}{c}{ Median range } \\
\cline { 2 - 4 } Parameter & Group C (12) & Group T1 (12) & Group T2 (9) \\
\hline P1/P2 ratio & $0.84,0.55-1.29$ & $0.88,0.74-5.00$ & $0.93,0.47-1.32$ \\
IVF rate & $76.5,60.0-100.0$ & $0.0,0.0-50.0$ & $25.0,0.0-42.9$ \\
$(\%)$ & & & \\
\hline
\end{tabular}

${ }^{a}$ Figure in parentheses represents number of patients analyzed.

in the $\mathrm{P} 1 / \mathrm{P} 2$ ratio. These three patients (14\%) were removed from the test groups and renamed group $\mathrm{Ab}$. The patients remaining in $\mathrm{T} 1$ and $\mathrm{T} 2$ groups had $\mathrm{Pl} /$ $\mathrm{P} 2$ ratios within the range of group $\mathrm{C}$, i.e., 0.64-1.26. These two groups were therefore pooled to make a single test group T3. Comparison of the $\mathrm{P} 1 / \mathrm{P} 2$ ratios for $\mathrm{Ab}$ with $\mathrm{C}$ and $\mathrm{T} 3$ showed no significant difference. Failure of significance could be due to the small size of group $A b$, which may reduce the sensitivity of this statistical test. The median and range of $\mathrm{P} 1 / \mathrm{P} 2$ ratios for the three groups are shown in Table II. The gel electrophoresis patterns of basic protein extracts (Fig. 1) from semen of patients in group $A b$ were examined and visually compared with extracts of control patients with normal P1/P2 ratios. Patients 22, 29, and 31 had unusually high proportions of histones, which suggests that the histones (or histone-like proteins of the same mobility) persist in these patients.

Correlations between $\mathrm{P} 1 / \mathrm{P} 2$ ratios and other sperm parameters were statistically investigated for groups $\mathrm{C}, \mathrm{T} 3$, and Ab. Table III summarizes the results. PI/ $\mathrm{P} 2$ ratio was found to correlate negatively with IVF rates in group $\mathrm{C}\left(R_{s}=-0.6119 ; P \leq 0.05\right)$ and to progressive motile sperm concentrations in group T3 $\left(R_{s}=-0.7436, P \leq 0.01\right.$ ) (Table III). Similar trends were identified among P1/P2 ratio, IVF rates, and progressive motile sperm concentration for group $\mathrm{Ab}$ patients, although this group was too small $(n=3)$ for nonparametric tests to be performed.

In an attempt to see if the correlation between P1/ $\mathrm{P} 2$ ratio and progressive motile sperm concentration is real, we investigated it in a new group called IVF. Group IVF consisted of all control and test patients with normal $\mathrm{P} 1 / \mathrm{P} 2$ ratios that attended the IVF clinic for fertility treatment $(C+\mathrm{T} 3 ; n=30)$. Group IVF median values were recalculated from values of patients belonging to group $\mathrm{C}$ and T3. Progressive motile sperm concentration was found to correlate negatively with $\mathrm{P} 1 / \mathrm{P} 2$ ratio $\left(R_{s}=-0.4798, P \leq 0.01\right)$ for this group also, supporting the existence of a relationship between these two parameters. 
Table III. Group C, T3, and Ab Median and Range Values for P1/P2 Ratios, IVF Rates, Sperm Concentration, Total Sperm Count, Progressive Motile Sperm Concentration, Percentage Morphologically Normal Papanicolaou-Stained Sperm (PAP Normal Sperm), Sperm Head Dimensions, Percentage Mature Sperm Lacking Histones (nb Sperm), and Percentage Mature Sperm with Double-Stranded DNA (DS-DNA)

\begin{tabular}{|c|c|c|c|}
\hline \multirow[b]{2}{*}{ Parameter } & \multicolumn{3}{|c|}{ Median, range } \\
\hline & Group C & Group T3 & Group $\mathrm{Ab}$ \\
\hline $\mathrm{P} 1 / \mathrm{P} 2$ ratio & $(12)^{a} 0.84,0.55-1.29$ & (18) $0.90,0.64-1.26$ & (3) $1.32,0.47-5.00$ \\
\hline IVF rate (\%) & (12) $76.5,60.0-100.0^{b}$ & (18) $0.0,00.0-50.0^{4}$ & (3) $25.0,21.4-33.3^{d}$ \\
\hline Sperm concentration $\left(\times 10^{6} / \mathrm{ml}\right)$ & $\begin{array}{l}\text { (12) } 139.50 \\
14.80-753.00\end{array}$ & $\begin{array}{l}\text { (18) } 54.25 \\
11.40-311.00\end{array}$ & $\begin{array}{l}\text { (3) } 21.43 \\
9.60-148.00\end{array}$ \\
\hline Total sperm count $\left(\times 10^{6}\right)$ & $\begin{array}{l}\text { (12) } 338.25 \\
66.60-1124.00\end{array}$ & $\begin{array}{c}\text { (18) } 109.44 \\
8.28-1088.50^{d}\end{array}$ & $\begin{array}{l}\text { (3) } 58.56 \\
9.60-333.00\end{array}$ \\
\hline $\begin{array}{l}\text { Progressive motile sperm } \\
\text { concentration }(\times 10 / \mathrm{ml})\end{array}$ & (12) $71.71,6.22-519.57$ & $\begin{array}{c}\text { (18) 21.03, } \\
3.42-160.68^{c, c^{3}}\end{array}$ & (3) $4.26,4.13-87.32$ \\
\hline PAP normal sperm (\%) & (12) $11.3,2.0-19.5$ & (18) $6.0,1.0-10.5^{d}$ & (3) $6.0,4.5-6.5$ \\
\hline Sperm head area $\left(\mu \mathrm{m}^{2}\right)$ & (10) $7.63,7.26-8.83$ & (16) $8.04,6.94-10.20$ & (3) $9.12,9.08-9.64^{d}$ \\
\hline Sperm head perimeter $(\mu \mathrm{m})$ & (10) $11.10,10.80-12.00$ & $\begin{array}{c}\text { (16) } 11.25 \\
10.50-12.70\end{array}$ & $\begin{array}{c}\text { (3) } 12.30 \\
12.10-12.50^{d . e}\end{array}$ \\
\hline Sperm head breadth $(\mu \mathrm{m})$ & (10) $2.68,2.64-2.89$ & (16) $2.71,2.50-3.03$ & $\begin{array}{c}\text { (3) } 2.89 \\
2.88-2.93^{d, e}\end{array}$ \\
\hline Sperm head length $(\mu \mathrm{m})$ & (10) $3.94,3.76-4.22$ & (16) $4.02,3.04-4.51$ & $\begin{array}{l}\text { (3) } 4.39 \\
4.36-4.54^{d, e}\end{array}$ \\
\hline $\begin{array}{l}\text { Sperm head roundness } \\
\text { nb sperm }(\%)\end{array}$ & $\begin{array}{l}\text { (10) } 1.24,1.21-1.27 \\
\text { (12) } 62.8,47.5-79.0\end{array}$ & $\begin{array}{l}\text { (15) } 1.23,1.19-1.27 \\
\text { (14) } 21.5,13.0-56.0^{4}\end{array}$ & $\begin{array}{l}\text { (3) } 1.25,1.24-1.27 \\
\text { (2) } 32.0,27.0-37.0^{d}\end{array}$ \\
\hline DS-DNA (\%) & (12) $52.0,30.0-59.0$ & (18) $36.5,10.0-48.0^{d}$ & (3) $35.0,25.0-39.0$ \\
\hline
\end{tabular}

\footnotetext{
a Figure in parentheses represents number of patients analyzed.

${ }^{b} \mathrm{P} \leq 0.05$, correlation identified for group $\mathrm{C} \mathrm{Pl} / \mathrm{P} 2$ ratios.

c $\mathrm{P} \leq 0.01$, correlation identified for group T3 P1/P2 ratios.

${ }^{d} \mathrm{P} \leq 0.05$, significantly different from group $\mathrm{C}$.

e $P \leq 0.05$, significantly different from group $\mathrm{T} 3$.
}

Sperm smears from all patients under study were stained with acidic aniline blue and acridine orange. Staining with acidic aniline blue indicates the presence of lysine-containing histones, hence lack of histone removal during spermiogenesis. Sperm heads still containing histones stain completely or partially blue with acidic aniline blue. Sperm heads in which histones have been replaced by protamines do not stain (negative staining for histones).

In addition to having low numbers of progressively motile sperm, Ab patients also had low proportions of sperm lacking histones (32\%; supporting gel observations) or double-stranded DNA (35.0\%) compared to group C (62.8 and 52.0\%, respectively, Table III). Group T3 showed values similar to group Ab's for aniline blue and acridine orange staining. Other sperm parameters for the Ab group were compared to groups C, T3, and IVF in an attempt to determine if any of the parameters measured during IVF procedure could identify $\mathrm{Ab}$ patients with abnormal P1/P2 ratios. Of the sperm parameters compared, only sperm head dimensions were found to differ significantly between group $\mathrm{Ab}$ and groups $\mathrm{C}, \mathrm{T} 3$, and IVF. Group $\mathrm{Ab}$ had significantly larger median sperm head perimeter, breadth, and length values $(P \leq 0.05)$ than did all other groups (Table III). Figure 2 represents these differences graphically in the form of Box Whisker plots.

On detailed examination of patient data, two other test patients (patients 28 and 29) with $\mathrm{P} 1 / \mathrm{P} 2$ ratios within control range also exhibited head dimensions greater than those of control and other test patients. These two patients were similar to the $\mathrm{Ab}$ group regarding fertilization rates (patient $28,20.0 \%$; patient $29,25.0 \%$ ), progressive motile concentration (patient $28,26.0 \times 10^{6}$; patient $29,4.26 \times 10^{6}$ ); or proportion of morphologically normal sperm stained with Papanicolaou (patient $28,8.5 \%$; patient $29,4.5 \%$ ); aniline blue (patient $28,18.0 \%$; patient $29,37.0 \%$ ), and acridine orange (patient 28,38.0\%; patient 29, 25.0\%) (Table III). From this it appears that large head dimensions are not exclusive to patients with aberrant ratios.

\section{DISCUSSION}

Protamines were extracted from sperm samples donated by 33 male patients attending an infertility clinic and $\mathrm{P} 1 / \mathrm{P} 2$ ratios determined for each patient. In all 33 couples female infertility factors were excluded. Twelve patients who had fertilization rates ranging 

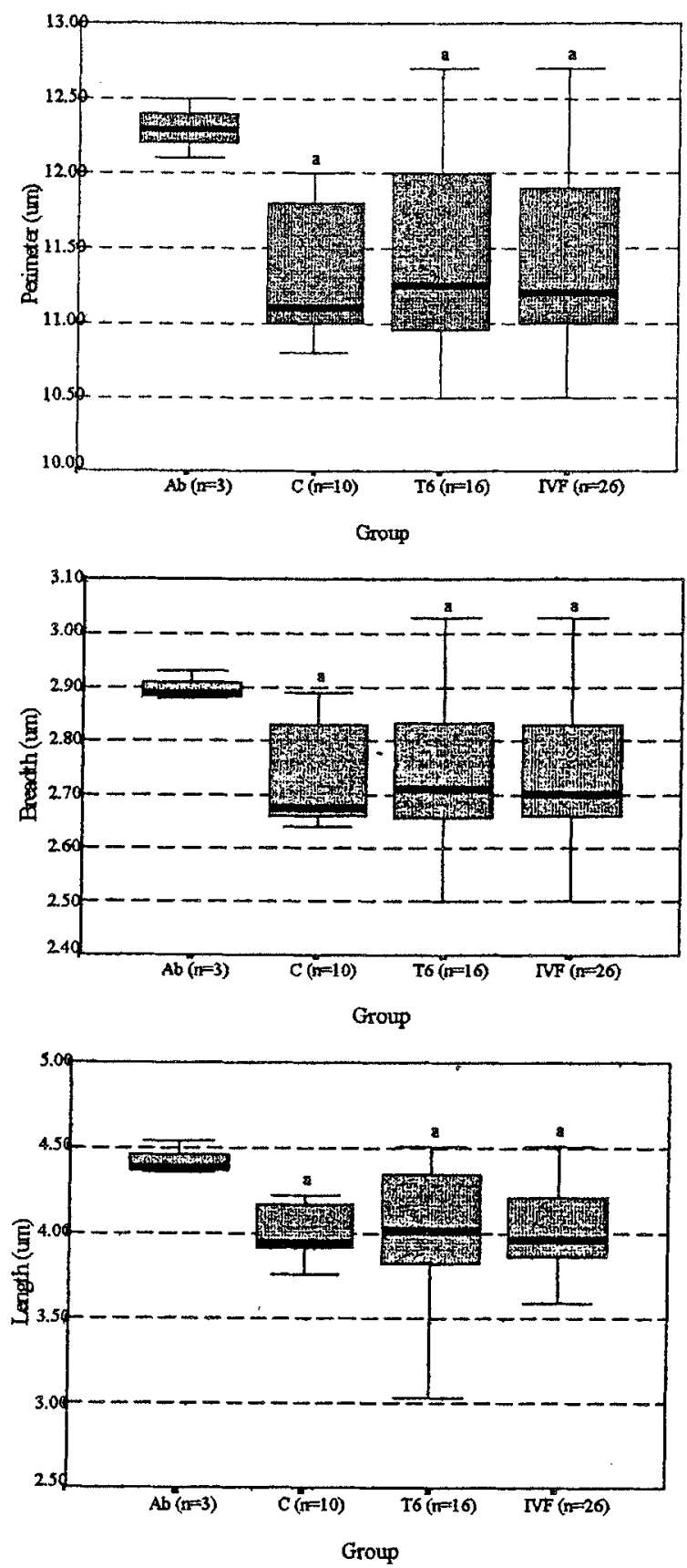

Fig. 2. Box-Whisker plots showing the sperm head dimensions: perimeter, breadth, and length for groups $A b, C, T 3$, and IVF. Mann-Whitney $U$ test showed that when group Ab was compared to all other groups, significant differences existed. $n=$ number of patients analyzed. ${ }^{\mathrm{a}} P \leq 0.05$, compared to group $\mathrm{Ab}$. from 60 to $100 \%$ and had achieved a pregnancy in one IVF cycle were designated the control group. The other 21 patients were designated test patients because of very low rates of fertilization. The $\mathrm{P} 1 / \mathrm{P} 2$ ratio for the whole group of patients ranged from 0.47 to 5.00 . Median P1/P2 ratio values were consistently higher in test groups than in control groups as found in previous studies $(2,10,14-15,16)$, although the difference was not statistically significant. Previous studies have failed to compare statistically ratios between test and control patients or to isolate test and control patients with low $\mathrm{P} 1 / \mathrm{P} 2$ ratios, as identified in the present study. In the study carried out by Balhorn et al. (2), 17 fertile patients exhibited a $\mathrm{P} 1 / \mathrm{P} 2$ ratio range of $0.85-1.27$, and 7 infertile patients a range of 1.22-1.93. In the study by Belokopytova et al. (16), 20 fertile patients had a P1/P2 ratio range of $0.87-1.10$ and 10 infertile patients a range of 1.44-1.56. de Yebra et al. (10) reported $\mathrm{P} 1 / \mathrm{P} 2$ ratios for infertile patients in the range of $0.92-15.52$, thus suggesting that it is possible for test patients to exhibit ratios higher than exhibited in our study. The range of P1/P2 in our study overlaps extensively with that reported by other studies for fertile patients $(2,10,16)$. It therefore appears that this range of variation still requires further investigation in both control and test patients.

In our study only 3 of the 21 test patients (14\%) had $\mathrm{P} 1 / \mathrm{P} 2$ ratios outside the range of the control group. Balhorn et al. (2) found that 6 of 7, Belokopytova et al. (16) found that 10 of 10, and Yebra et al. (10) found that 90 of 116 of their test patients had altered $\mathrm{P} 1 / \mathrm{P} 2$ ratios in comparison to their control groups. The discrepancies among these studies may be explained by different criteria for classification of infertile males, group sizes as well as methods to quantify protamine bands, and the definition of the normal P1/P2 ratio range. These differences make direct comparisons difficult.

Several semen parameters were investigated in an attempt to identify those that may reflect $\mathrm{P} 1 / \mathrm{P} 2$ ratio changes. Such parameters would provide the potential to understand the role of $\mathrm{P} 1$ and $\mathrm{P} 2$ in dictating spermatozoa phenotype or function and could be used to predict aberrant ratios.

P1/P2 ratios were statistically negatively correlated with IVF rates in group $C$ and to progressive motile sperm concentration in group $\mathrm{T} 3$. The negative correlation between progressive motile sperm concentration and $\mathrm{P} 1 / \mathrm{P} 2$ ratios persisted when all the patients seeking infertility treatment were grouped together (group IVF). This trend was also identified in the Ab group. No common parameter was found to reflect $\mathrm{P} 1 / \mathrm{P} 2$ ratio 
in all the groups studied. From this it may be suggested that a low progressive motile sperm concentration may be associated with protamine ratios. This parameter, however, lacks sensitivity in identifying patients with abnormal P1/P2 ratios, as some test patients in this study exhibited a progressive motile sperm concentration similar to that exhibited by Ab patients but had normal $\mathrm{P} 1 / \mathrm{P} 2$ ratios as exhibited by group $\mathrm{C}$.

The complete overlap of $\mathrm{P} 1 / \mathrm{P} 2$ ratios between patients in the control group with high fertilization rates resulting in pregnancy and patients in the $\mathrm{T} 3$ group with 0 or very low fertilization rates indicates that protamine levels are not a major factor in determining IVF rates. Moreover, the three patients with abnormal P1/P2 ratios showed some level of fertilization Table III. The negative correlation of P1/P2 ratio with fertilization rate in the control group may indicate a range of subfertility, since these patients needed infertility treatment.

The three patients in the Ab group showed statistically higher sperm head dimensions (Table III), when apparently morphologically normal sperm heads, stained with Feulgen, were measured by image analysis. However, two other test patients exhibited similarly large head dimensions but had normal P1/P2 ratios. It therefore appears that head dimensions may not be exclusively a result of aberrant $\mathrm{P} 1 / \mathrm{P} 2$ ratios and may involve other unidentified defects during spermatid maturation. van Duijn et al. (34) and Schmassman et al. (20) showed sperm head dimensions to be higher in subfertile patients than in fertile patients, although these studies did not look at sperm protamine levels. The head dimensions reported by van Duijn et al. (34) were similar to our findings. Thompson et al. (28) also studied sperm head dimensions and showed that sperm that bind to the zona pellucida have different head dimensions than sperm that do not. Larger head dimensions have been associated with either a higher or a lower DNA content, oligozoospermia, and subfertility $(19,20,35)$. Patient 22 in our study had large heads and was also oligozoospermic $\left(9.6 \times 10^{6}\right)$.

A common feature to all test patients was a significantly lower percentage of mature sperm staining negatively for histones compared to the control group (Table III). Other studies $(14,21,22,35)$ have demonstrated that persistence of histones, histone-like proteins, and protamine precursors in sperm results in abnormal sperm morphology and is associated with infertility.

Another common feature to all test patients was a lower proportion of sperm with double-stranded DNA then the control group, which is in agreement with previous studies $(23,24,29,36,37)$. However, patients possessing a high percentage of mature sperm with single-stranded DNA are still capable of fertilization, as $\mathrm{Ab}$ patients had a median fertilization rate of $25.0 \%$. Previous studies have supported this finding $(23,36)$.

Studies carried out on animals which possess the P2 gene but produce no or low levels of protamine 2 $(12,13,38,39)$ have suggested that reduction in either $\mathrm{P} 1$ or P2 may be explained by either reduced protamine transcription and translation or unstable products as a result of failed posttranscriptional modification. Lack of $\mathrm{P} 2$ in the boar has been shown to be due to mutations within the P2 gene (3l). Little work has been done on humans in relation to altered $\mathrm{P} 1 / \mathrm{P} 2$ ratios. Balhorn et al. (2) have shown that a decrease in P2 cannot be explained by an increase in P1 and de Yebra $e t$ al. (10) also found P1 levels to be conserved in patients with no P2. de Yebra et al. (10) also sequenced the gene and the promoter region, up to -200 base pairs from the transcription start site, of the four patients that showed complete absence of $\mathrm{P} 2$, but failed to identify any mutations.

Gene nucleotide and amino acid sequence analysis has led to the suggestion that intermediate proteins in sperm heads are P2 precursor proteins $(31-33)$. The presence of such intermediates in patients that have low P2 may indicate the presence of the P2 gene product (Fig. 1). Patient 22 appeared to exhibit such intermediates. Round cells, however, need to be removed from semen samples before protein extraction and electrophoretic separation to ensure histone and intermediate proteins are truly of sperm origin and not due to contamination with round cells.

In conclusion, our study investigated IVF rates and showed that low levels of $\mathrm{P} 1$ or $\mathrm{P} 2$ are associated with reduced fertilization as suggested by others. Such patients also had reduced proportions of sperm with normal Papanicolaou morphology, progressive motility, double-stranded DNA, negative staining for hislones, and head dimensions in the normal range. However, a number of test patients showed all these characteristics but had $\mathrm{P} 1 / \mathrm{P} 2$ ratios within the range of control patients. Therefore protamine levels may not be the primary cause of reduced fertilization and absence of pregnancy, although they may contribute to it. Impaired spermatogenesis, due to other factors, may affect all this and may also lead to altered protamine levels. Further studies will help to understand how the two forms of protamines cooperate in performing sperm head condensation and the mechanism by which altered proportions of any one protamine may interfere with fertility. 


\section{ACKNOWLEDGMENTS}

Many thanks go to the patients who kindly volunteered to be involoved in this research. Great appreciation is due to Dr. M. A. Warren at Sheffield University for providing the image analyzer. Much gratitude goes to The Gift of a Life Appeal for providing the funding for this research project and to R. D. Catalano for stimulating this research.

\section{REFERENCES}

1. Bellvé AR: The molecular biology of mammalian spermatogenesis. Oxford Rev Reprod Biol 1979;1:159-261

2. Balhorn R, Reed S, Tanphaichitr N: Abertant protamine 1/ protamine 2 ratios in sperm of infertile human males. Experientia $1988 ; 44: 52-55$

3. Kleene KC, Distel RJ, Hecht NB: Nucleotide sequence of cDNA clone encoding mouse protamine 1. Biochemistry $1985 ; 24: 719-722$

4. Oliva R, Dixon GH: Vertebrate protamine genes and the histone-to-protamine replacement reaction. Proc Nucleic Acid Res Mol Biol 1991;40:25-94

5. Elsevier SM: Messenger RNAs encoding basic chromosomal proteins of mouse testis. Dev Biol 1982;90:1-12

6. Kleene KC, Distel RJ, Hecht NB: Translational regulation and deadenylation of a protamine mRNA during spermiogenesis in the mouse. Dev Biol 1984;105:71-79

7. Poccia D: Remodelling of nucleoproteins during gametogenesis, fertilization and early development. Int Rev Cytol 1986;105:1-65

8. McKay DJ, Renaux BS, Dixon GH: The animo acid sequence of human sperm protamine P1. Biosci Rep 1985;5:383-391

9. McKay DJ, Renaux BS, Dixon GH: Human sperm protamines. Amino acid sequences of two forms of protamine P2. Eur $J$ Biochem 1986;156:5-8

10. de Yebra L, Bakesca JL, Vanrell JA, Bassas L, Oliva R: Complete selective absence of protamine $\mathrm{P} 2$ in humans. Biol Chem 1993;268: 10553-10557

11. Calvin $\mathrm{HJ}$ : Comparative analysis of the nuclear basic proteins in rat, human, guinea pig, mouse and rabbit spermatozoa. Biochim Biophys Acta 1976;434:377-389

12. Bower PA, Yelick PAC, Hecht NB: Both P1 and P2 protamine genes are expressed in mouse, hamster and rat. Biol Reprod 1987;37:479-488

13. Maier W, Nussbaum G, Domenjoud L, Klemm U, Engel W: The lack of protamine $2(\mathrm{P} 2)$ in boar and bull spermatozoa is due to mutations within the P2 gene. Nucleic Acid Res 1990;18:1249-1254

14. Chevaillier P, Mauro N, Feneux D, Jouannet P, David G: Anomalous protein complement of sperm nuclei in some infertile men. Lancet 1987;2(8562):806-807

15. Bach O, Glander HJ, Scholz G, Schwarz J: Electrophoretic patterns of spermatozoal nucleoproteins (NP) in fertile men and infertile patients and comparison with NP of somatic cells. Andrologia 1990;22:217-224

16. Belokopytova IA, Kostylena EI, Tomlin AN, Vorobév VI: Human male infertility maybe due to a decrease of the prot- amine P2 content in sperm chromatin. Mol Reprod Dev 1993:34:53-57

17. Swanson RJ, Brugo S: New method of evaluating sperm morphology with predictive value for human in vitro fertilization. J Urol 1987;30(3):248-251

18. Brasch JG, Rawlins R, Tarchala S, Radwanaka E: The relationship between total motile sperm count and the sucess of intrauterine insemination. Fertil Steril 1994;62(1):150-154

19. Leuchtenberger C, Schrader F, Weir DR, Gentile DP: The deoxyribonucleic acid (DNA) content in spermatozoa of fertile and infertile human males. Chromosoma 1953;6:61-78

20. Schmassmann A, Mikuz G, Bartsch G, Gysin C, Rohr HP: Deoxyribonucleic acid (DNA) content of morphologically different sperm types from normal and subfertile human males. Andrologia 1981;13:33-41

21. Colleu D, Lescoat D, Boujard D, le Lannou D: Human spermatozoal nuclear maturity in normoospermia and asthenozoospermia. Arch Androl 1988;21:155-162

22. Auger J, Mesbah M, Huber $C$, Dadoune JP: Aniline blue staining as a marker of sperm chromatin defects associated with different semen characteristics discriminates between proven fertile and suspected infertile men. Int J Androl 1990;13: $452-462$

23. Ibrahim ME, Pedersen $\mathrm{H}$ : Acridine orange fluorescence as male fertility test. Arch Androl 1988;20:125-129

24. Tejada RI, Mitchell JC, Norman A, Mark JJ, Friedman S: A test for the practical evaluation of male fertility by acridine orange (AO) florescence. Fertil Steril 1984;42:87-91

25. World Health Organisation (eds): Collection and examination of semen. In WHO Laboratory Manual for the Examination of Human Semen and Sperm-Cervical Mucus Interaction. New York, Cambridge University Press, 1993, pp 3-21

26. de Yebra L, Oliva R: Rapid analysis of mammalian sperm nuclear proteins. Anal Biochem 1993;209:201-203

27. Cooke ID (ed): Feulgen stain. In Manual of Histology Demonstration Techniques. London, Butterworths, 1974

28. Thompson LA, Brook PF, Warren MA, Barratt CLR, Cooke ID: A morphometric comparison of the head morphology of fresh and frozen-thawed human zona-bound and unbound sperm. J Androl 1994;15:337-342

29. Liu DY, Baker HWG: Sperm nuclear chromatin normality: Relationship with sperm morphology, sperm-zona pellucida binding, and fertilisation rates in vitro. Fertil Steril 1992;58:1178-1184

30. Rees DG (ed): Non-parametric hypothesis tests. In Essential Statistics. London, Chapman and Hall; 1989, pp 12-25

31. Martinage A, Arkhis A, Alimi E, Sautière P, Chevaillier P: Molecular characterisation of nuclear basic protein HPIl, a putative precursor of human sperm protamines HP2 and HP3. Eur J Biochem 1990;191:449-451

32. Chauvière M, Martinage A, Debarle M, Sautière P, Chevaillier $\mathrm{P}$ : Molecular characterisation of six intermediate proteins in the processing of mouse protamine P2 precursor. Eur J Biochern 1992;204:759-765

33. Alimi B, Martinage A, Arkhis A, Belaiche D, Sautiere P, Chevaillier P: Amino acid sequence of the human intermediate protein 2 (HP12) from sperm nuclei: Structural relationship with protamine P2. Eur J Biochem 1993;214:445-450

34. van Duijn $\mathrm{C} J \mathrm{~J}$, van Voorst $\mathrm{C}$, Hellinga G: Precision measurements of dimensions, shape and mass density of spermatozoan heads in normal and subfertile human males. Eur $J$ Obstet Gynaecol 1972;2:37-54 
35. Silvestroni L, Frajese G, Malandrino F: Histones instead of protamines in terminal germ cells of infertile, oligozoospermic men. Fertil Steril 1976;27:1428-1437

36. Pedersen $\mathrm{H}$ : Ultrastructure of spermatozoa with abnormal morphology and predominately single-stranded DNA. Arch Androl 1987;19:97-105

37. Liu DY, Baker HWG: A new test for the assessment of spermzona pellucida penetration: Relationship with results of other sperm tests and fertilisation in vitro. Hum Reprod 1994;9:489-496

38. Stewart TA, Hecht NB, Hollingshsead PG, Johnson PA, Leong AC, Pitts S: Haploid-specific transcription of protamine-myc and protamine-T-antigen fusion genes in transgenic mice. Mol Cell Biol 1988;8:1748-1755

39. Bunick D, Balhorn R, Stanker LH, Hecht NB: Expression of the rat protamine 2 gene is suppressed at the level of transcription and translation. Exp Cell Res 1990;188:147-157 